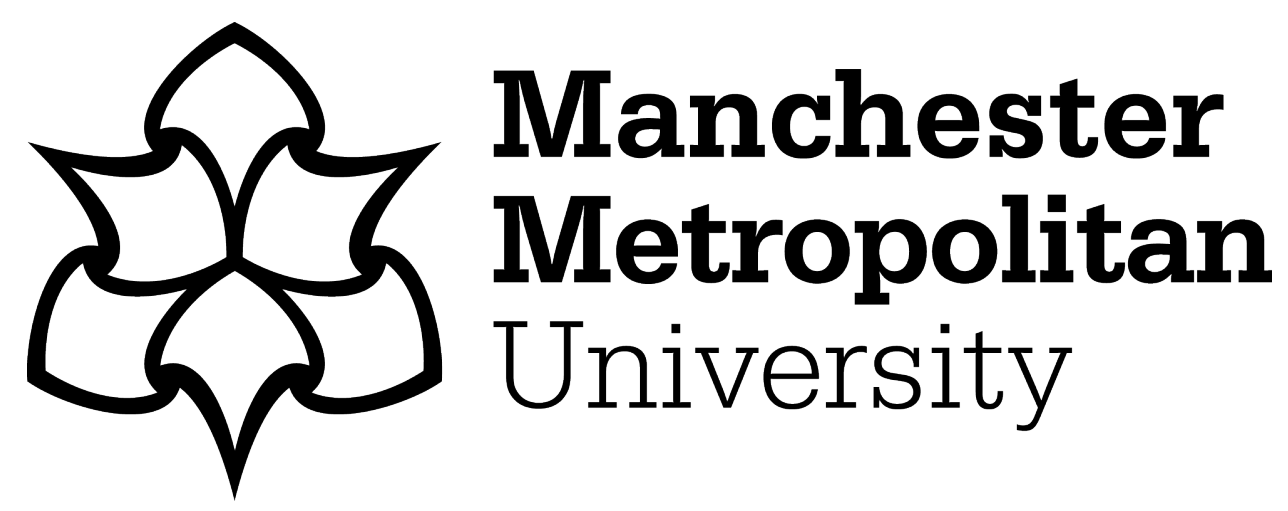

Regmi, YN ORCID logoORCID: https://orcid.org/0000-0001-6588-7683, Mann, JK, McBride, JR, Tao, J, Barnes, CE, Labbé, N and Chmely, SC (2017) Catalytic transfer hydrogenolysis of organosolv lignin using B-containing FeNi alloyed catalysts. Catalysis Today, 302. pp. 190-195. ISSN 0920-5861

Downloaded from: https://e-space.mmu.ac.uk/624773/

Version: Accepted Version

Publisher: Elsevier

DOI: https://doi.org/10.1016/j.cattod.2017.05.051

Usage rights: Creative Commons: Attribution-Noncommercial-No Derivative Works 4.0

Please cite the published version 


\title{
Catalytic transfer hydrogenolysis of organosolv lignin using B-containing FeNi alloyed catalysts
}

Yagya N. Regmi ${ }^{a}$, Jeffrey K. Mann ${ }^{\mathrm{a}}$, James R. McBride ${ }^{\mathrm{b}, \mathrm{c}}$, Jingming Tao ${ }^{\mathrm{a}}$, Craig E. Barnes ${ }^{\mathrm{d}}$, Nicole Labbéa ${ }^{\text {a }}$ Stephen C. Chmely ${ }^{\mathrm{a}, *}$

${ }^{a}$ Center for Renewable Carbon, University of Tennessee, Knoxville, TN 37996, USA

${ }^{\mathrm{b}}$ Department of Chemistry, Vanderbilt University, Nashville, TN 37240, USA

c Vanderbilt Institute of Nanoscale Science and Engineering, Vanderbilt University, Nashville, TN 37240, USA

${ }^{d}$ Department of Chemistry, University of Tennessee, Knoxville, TN 37996, USA

* Corresponding author. E-mail: schmely@utk.edu

Keywords: biomass, lignin, valorization, catalytic transfer hydrogenolysis, nanomaterials

\begin{abstract}
In this work, $\mathrm{FeB}, \mathrm{NiB}$, and $\mathrm{FeNiB}$ nanomaterials were examined as catalysts for catalytic transfer hydrogenolysis (CTH) using supercritical ethanol (sc-EtOH) as the hydrogen donor and reaction solvent. The earth-abundant alloys were synthesized using simple aqueous chemical reductions and characterized using ICP-OES, XRD, and STEM-EDS. Using acetophenone to model the desired catalytic reactivity, FeNiB was identified as having superior reactivity (74\% conversion) and selectivity for complete deoxygenation to ethylbenzene (84\%) when compared to the monometallic materials. Given its high reactivity and selectivity for deoxygenation over ring saturation, $\mathrm{FeNiB}$ was screened as a lignin valorization catalyst. FeNiB mediates deoxygenation of aliphatic hydroxyl and carbonyls in organosolv lignin via CTH in sc-EtOH. A combination of gel permeation chromatography, GC/MS, and NMR spectroscopy was used to demonstrate the production of a slate of monomeric phenols with intact deoxygenated aliphatic side chains. In total, these results highlight the utility of CTH for the valorization of biorefineryrelevant lignin using an inexpensive, earth-abundant catalyst material and a green solvent system that can be directly derived from the polysaccharide fraction of lignocellulosic biomass.
\end{abstract}

\section{Introduction}


Lignin is a multiaromatic heteropolymer produced by plants to provide strength and rigidity and to aid in water conduction. Since it is a renewable source of aromatic hydrocarbons, lignin is a potential platform for these valuable chemical synthons that are used in the production of myriad fine chemicals and products. Accordingly, several investigations have focused on the catalytic valorization of lignin in the context of the integrated biorefinery [1-5]. Recently, researchers have focused on so-called reductive catalytic fractionation (RCF), which is a family of processes that use various catalysts to upgrade lignin directly from whole biomass in a reducing environment [6-12]. Another related strategy for biomass valorization is based on organosolv fractionation, which first separates whole biomass into its major constituent fractions of cellulose, hemicellulose, and lignin [13, 14]. This methodology allows direct upgrading of components, which is an operationally attractive scheme for lignin valorization, given that the tunable process parameters allow for the isolation of lignin with specific properties [15].

Hydrogenolysis reactions of alcohols and carbonyls to produce alkanes are important in the context of biomass conversion to fuels and platform chemicals $[16,17]$. Since the oxygen content of biomass is substantially higher than that of those products, scalable and economical hydrodeoxygenation (HDO) reactions are needed to produce infrastructure-compatible products. Fractionation of biomass combined with HDO of the resulting fractions allows for condensedphase deoxygenation strategies to produce fuels, chemicals, and materials at scale. However, because the solubility of $\mathrm{H}_{2}$ in many organic solvents is low [18], high temperatures and excessive pressures of hydrogen gas are often required for liquid-phase HDO reactions of biomass fractions.

Owing to the safety concerns and operational complexity of high-pressure condensed-phase hydrogenations at scale, a vast body of research has been dedicated to transfer hydrogenation reactions [19]. In these schemes, a molecule (or equivalent) of $\mathrm{H}_{2}$ is transferred from a donor molecule to the reducible acceptor molecule. Hydrogen donor molecules are oftentimes inexpensive organic alcohols that can be directly derived from biomass. These liquid hydrogen donor molecules can also serve as the reaction solvent for hydroprocessing schemes. Under the right conditions (e.g. above the solvent critical point), HDO via transfer hydrogenation can occur (Scheme 1). Supercritical fluids simultaneously display the solvating power of a liquid and the penetrating power of a gas, and have been investigated as reaction media for myriad catalytic reactions involving conversion of biomass and its fractions [20, 21]. For example, Ford and co- 
workers have shown the utility of supercritical methanol for the catalytic transfer hydrogenolysis $(\mathrm{CTH})$ of furans and lignin using $\mathrm{Cu}$-based metal oxide catalysts $[22,23]$.

Scheme 1. CTH of acetophenone in ethanol using a hypothetical nanoparticle (NP) catalyst.

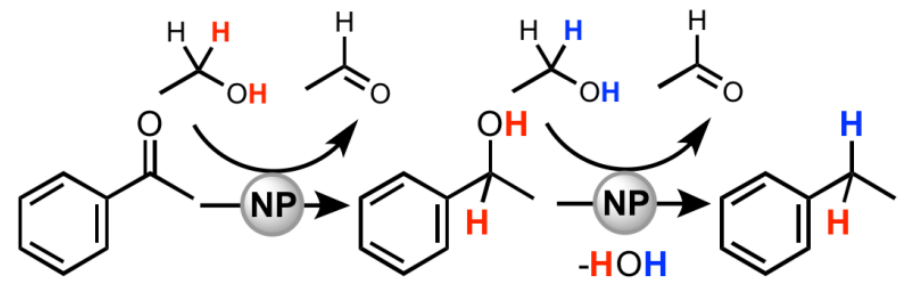

Although several examples of materials capable of mediating CTH of polysaccharide fractions are known in the literature, far fewer of these investigations have focused on $\mathrm{CTH}$ of lignin [17]. Rinaldi and coworkers have investigated Raney Ni for CTH of lignin-derived phenols [24]. They found that the catalyst was particularly active for HDO of phenolic compounds. But at the same time, they demonstrated that the catalyst simultaneously affords ring saturation products. This reactivity is undesirable to produce aromatic chemicals, but is particularly attractive if the target of conversion is a saturated fuel mixture. In contrast, Song et al. demonstrated that $\mathrm{Ni} / \mathrm{C}$ catalysts could catalyze $\mathrm{CTH}$ of phenolic lignin monomers derived from birch wood lignin to provide partially deoxygenated products that retain their aromatic character [11]. Recently, Jae and coworkers demonstrated that RuRe/C catalysts are effective for HDO of guaiacol [25]. They concluded that the alloy of Re and Ru in the catalyst enhances reactivity, but also noted that the major product is ring-saturated cyclohexanol.

Boron-containing metal alloys have been the subject of numerous studies given their interesting mechanical, electronic, and catalytic properties [26, 27]. B-containing alloys of FeNi have been used for the liquid-phase catalytic hydrogenation of p-chloronitrobenzene [28]. Moreover, B-containing alloys of CoMo [29], NiMo [30, 31], and LaNiW [32] have been investigated for $\mathrm{HDO}$ of phenolic compounds using high-pressure $\mathrm{H}_{2}$ gas. In addition, $\mathrm{NiB}$ generated within the cellular structure of milled wood powders has been shown to be an effective and selective lignin hydrogenolysis catalyst [33]. However, these catalysts have not been investigated as catalytic transfer hydrogenolysis mediators, even though they display a propensity for mediating reductive transformations, including HDO reactions of lignin and lignin model compounds. 
Here, we report on the ability of B-containing FeNi nano alloys to mediate catalytic transfer hydrogenolysis $(\mathrm{CTH})$ reactions in supercritical ethanol (sc-EtOH). We have produced the alloyed and the monometallic materials by facile chemical reduction reactions using $\mathrm{NaBH}_{4}$, and we reveal the amorphous nature of the materials using x-ray diffractometry (XRD) and scanning transmission electron microscopy (STEM). We use energy-dispersive x-ray spectroscopy (EDS) to confirm the alloyed nature of the bimetallic species. We note the superior selectivity for the complete deoxygenation of acetophenone to ethylbenzene in supercritical ethanol using the alloyed material instead of the constituent monometallic materials. Finally, we apply CTH in scEtOH to organosolv lignin from Populus deltoides (hybrid poplar) using the alloyed material to afford partially deoxygenated, depolymerized products. We monitor changes in molecular weight of the lignin before and after catalysis using gel permeation chromatography (GPC), and we identify some deoxygenated monomeric products using GC/MS. We also use ${ }^{1} \mathrm{H}-{ }^{13} \mathrm{C}$ HSQC NMR spectroscopy to demonstrate the utility of the catalyst species to deoxygenate aliphatic hydroxyl and carbonyl groups in the presence of unsaturated $\mathrm{C}=\mathrm{C}$ bonds and aromatic hydroxyl groups in biorefinery-relevant lignin. Taken together, these results demonstrate the utility of the combination of an earth-abundant catalyst and a biomass-derived solvent to valorize lignin without the addition of external hydrogen.

\section{Materials and methods}

\subsection{Catalyst preparation}

All reagents were obtained from commercial vendors and were used as received. The alloy catalysts were prepared using a modified synthesis method reported by Nie et al. [34]. To prepare B-containing FeNi nano alloys, $0.3 \mathrm{M}$ aqueous solutions of $\mathrm{NiCl}_{2} \cdot 6 \mathrm{H}_{2} \mathrm{O}$ and $\mathrm{FeCl}_{3} \cdot 6 \mathrm{H}_{2} \mathrm{O}$ were prepared, and $20 \mathrm{~mL}$ of each were mixed by magnetic stirring at $300 \mathrm{rpm}$ to obtain equimolar ratio of $\mathrm{Fe}^{3+}$ and $\mathrm{Ni}^{2+}$ ions. The solution was equilibrated at $75^{\circ} \mathrm{C}$ and then $150 \mathrm{~mL}$ of freshly prepared $0.2 \mathrm{M}$ aqueous solution of $\mathrm{NaBH}_{4}$ was added dropwise. To prepare Bcontaining $\mathrm{Fe}$ and $\mathrm{Ni}$ catalysts, the volume of $\mathrm{NaBH}_{4}$ was adjusted so that the metal ions $\left(\mathrm{Fe}^{3+}\right.$ and $\mathrm{Ni}^{2+}$ ) are reduced to their metallic states (Fe and $\mathrm{Ni}$ ). The resulting suspension was filtered and the black precipitate washed with copious amount of deionized water. The precipitate was dried in a vacuum oven at $60{ }^{\circ} \mathrm{C}$ for 2 hours before grinding into a fine powder using an agate mortar and pestle.

\subsection{Catalyst characterization}


XRD was performed using a Panalytical Empyrean diffractometer with a $\mathrm{Cu} \mathrm{K}$-alpha 1 (high resolution) source $(\lambda=0.15406 \mathrm{~nm})$ using a voltage of $45 \mathrm{kV}$ and a current of $40 \mathrm{~mA}$. STEMEDS was performed using a Tehai Osiris operating at $200 \mathrm{kV}$ with a probe current on the order of $1.5 \mathrm{nA}$. The instrument is equipped with a SuperX EDS system which is composed of four windowless solid state detectors that allow for light element detection down to and including boron. Inductively-coupled plasma optical emission spectroscopy (ICP-OES) measurements were performed on an Optima 7300 DV spectrometer from PerkinElmer.

\subsection{Extraction of lignin from hybrid poplar using an organosolv process}

The biomass was fractionated using a method reported by Bozell and coworkers [14]. Hybrid poplar chips ( $\sim 660 \mathrm{~g})$ were loaded in a flow-through reactor and impregnated with a 16/34/50 $\mathrm{wt} \%$ solution of methyl isobutyl ketone, ethanol, and water, respectively, with sufficient sulfuric acid to make a $0.05 \mathrm{M}$ solution. The reactor was electrically heated to $140{ }^{\circ} \mathrm{C}$ while fractionation solution was pumped through the reactor for $2 \mathrm{~h}$ at a rate sufficient to generate an ultimate solvent to biomass ratio of 14:1. After $2 \mathrm{~h}$, all the liquor was collected and $\mathrm{NaCl}$ (15 g per 100 $\mathrm{mL}$ ) was added to induce an aqueous-organic phase separation. The organic phase was washed with water $(2 \times 30 \% \mathrm{v} / \mathrm{v})$ and concentrated. The resulting material was triturated with diethyl ether $(5 \times 50 \mathrm{~mL})$, suspended in water ( $5 \%$ solids loading), and stirred overnight to afford a brown solid that was filtered and dried overnight in a vacuum oven at $80{ }^{\circ} \mathrm{C}$.

\subsection{Catalytic experiments}

\subsubsection{Catalytic transfer hydrogenolysis (CTH) of acetophenone}

A stock solution containing acetophenone $(1.0 \mathrm{~mL}, 8.6 \mathrm{mmol})$ and naphthalene $(1.0 \mathrm{~mL}, 3.4$ $\mathrm{mmol})$ in absolute ethanol $(8.0 \mathrm{~mL})$ was prepared $(10 \mathrm{~mL}$ total volume $)$. A micro reactor that consists of a 0.5 " MNPT stainless steel pipe fitting (Swagelok, P/N: SS-8-HN) and a pair of 0.5" FNPT stainless steel pipe caps (Swagelok, P/N: SS-8-CP) was charged with $10 \mathrm{mg}$ catalyst and $1.0 \mathrm{~mL}$ of the above stock solution. The reaction mixture was diluted with $7.0 \mathrm{~mL}$ absolute ethanol and sealed using Teflon tape to ensure a tight seal. The reactor was placed in a preheated muffle furnace at $320^{\circ} \mathrm{C}$ for the specified time. After this time, the reactor was removed and placed in an ice water bath to rapidly quench the reaction. The reactor was allowed to equilibrate with the ice water bath for 10 minutes, after which time it was carefully opened and a $10 \mu \mathrm{L}$ aliquot was removed for analysis by GC/MS. Caution! Acetaldehyde, the product of 
dehydrogenation of ethanol, has a boiling point of $20^{\circ} \mathrm{C}$. Opening the reactor directly after removal from the ice water bath helps to prevent rapid escape of gaseous acetaldehyde.

\subsubsection{CTH of organosolv lignin}

The CTH of organosolv lignin was performed in a similar manner as above using a stainlesssteel micro reactor. For this reaction, $50 \mathrm{mg}$ catalyst and $500 \mathrm{mg}$ of lignin were added directly to the reactor. Then, $7 \mathrm{~mL}$ of absolute ethanol and $1 \mathrm{~mL}$ hexadecane (internal standard) were added. The reactor was sealed, heated, quenched, and opened in an identical manner to above. Once the reactor was opened, the contents were transferred to a flask, and the reactor was rinsed with additional absolute ethanol to ensure quantitative transfer. Then, using a strong magnet, the ferromagnetic catalyst material was collected on one side of the flask and the contents were decanted. The remaining catalyst was rinsed with absolute ethanol three times, and the combined organic products were concentrated using a rotary evaporator to afford a viscous brown oil that was characterized as outlined below.

\subsection{Characterization of catalytic products}

GC/MS analyses of all CTH reactions (acetophenone and lignin) were performed using an Agilent 7890B GC system equipped with an Agilent HP-5ms capillary column coupled to an Agilent 5977A MSD. Using He carrier gas with a flow rate of $0.5 \mathrm{~mL} / \mathrm{min}$, the oven parameters were as follows: initial hold after injection at $50{ }^{\circ} \mathrm{C}$ for $2.5 \mathrm{~min}$, ramp at $15^{\circ} \mathrm{C} / \mathrm{min}$ to $275^{\circ} \mathrm{C}$ and hold for $5 \mathrm{~min}$.

Lignin molecular weight (MW) analyses were performed on a Tosoh EcoSEC gel permeation chromatography (GPC) system with a refractive index (RI) detector equipped with a flow reference cell. Lignin samples were subjected to acetobromination to increase their solubility using a procedure described elsewhere [35]. The instrument and reference cell flowrates set to $0.35 \mathrm{~mL} / \mathrm{min}$ and the analysis was performed at $40{ }^{\circ} \mathrm{C}$. Sample injections of $10 \mu \mathrm{L}$ were separated using 2 Tosoh TSKgel SuperMultiporeHZ-M columns (4.6 mm I.D., $150 \mathrm{~mm}$ length, 4 $\mu \mathrm{m}$ particle size) and a TSKgel SuperMultiporeHZ-M guard column using a total run time of 15 minutes. Polystyrene standards were used for a calibration range of $600-6.9 \times 10^{6} \mathrm{Da}$.

Band-selective gradient heteronuclear $\left({ }^{1} \mathrm{H}-{ }^{13} \mathrm{C}\right)$ single quantum coherence (HSQC) NMR spectroscopy was performed using a Varian 400-MR spectrometer equipped with a broadband probe operating at $399.78 \mathrm{MHz}$ for ${ }^{1} \mathrm{H}$ and $100.54 \mathrm{MHz}$ for ${ }^{13} \mathrm{C}$. Samples were prepared using $\sim 50 \mathrm{mg}$ lignin and $0.75 \mathrm{~mL}$ DMSO- $\mathrm{d}_{6}$. Data collection and processing were performed as 
reported previously by Bozell [36]. Data was collected using 512 increments and 32

scans/increment in the $\mathrm{F} 2$ dimension. A $90^{\circ}$ pulse with a relaxation delay of $1.5 \mathrm{~s}$ and a one-bond C-H coupling constant of $147.0 \mathrm{~Hz}$ were employed. The free induction decays (FIDs) were processed using a $t_{1}$ noise reduction algorithm, a third-order Bernstein polynomial baseline fit, and Lorentz-to-Gauss apodization using an exponential function of $-0.5 \mathrm{~Hz}$ and a Gaussian function of $10 \mathrm{~Hz}$ in the F2 dimension an exponential of $-10.0 \mathrm{~Hz}$ and a Gaussian function of 90 $\mathrm{Hz}$ in the $\mathrm{F} 1$ dimension.

\section{Results and discussion}

\subsection{Catalyst synthesis and characterization}

The putative catalyst materials were synthesized by chemical reduction of the corresponding chloride salts using $\mathrm{NaBH}_{4}$ in water without any attempts to exclude air. Reduction of the metal ions was complete typically in a matter of minutes, as indicated by the formation of a dark black ferromagnetic precipitate and the cessation of hydrogen gas evolution. We used ICP-OES to determine the atomic ratios for each material, and these data and the corresponding $\mathrm{x}$-ray diffraction patterns are displayed in Fig 1.

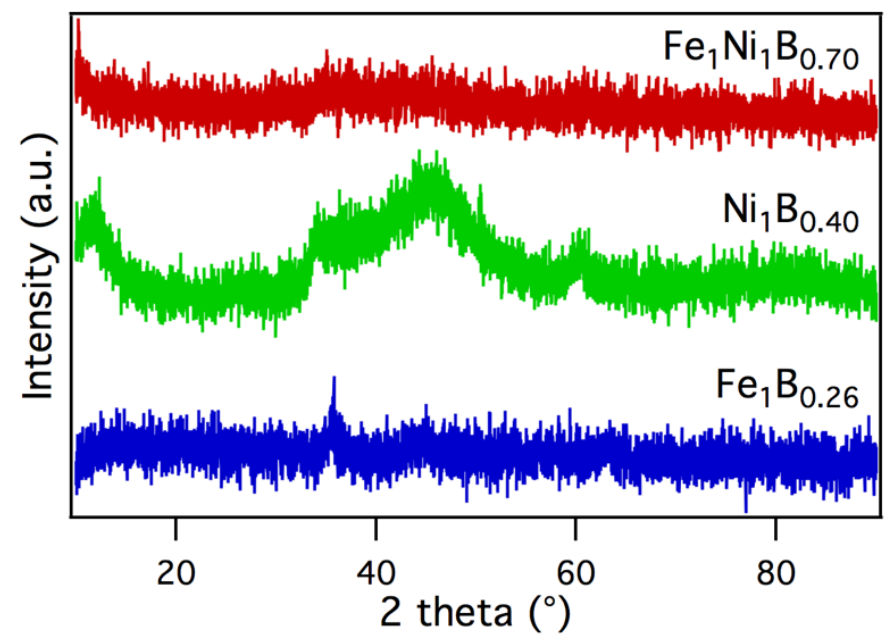

Fig 1. X-ray diffraction patterns of the as-synthesized materials. The atomic ratios (subscripts) were determined using ICP-OES.

The broad feature around $45^{\circ} 2 \theta$ in the XRD pattern for NiB has been previously noted for this material $[28,34]$. Otherwise, we note the absence of crystalline phases in any of the materials as evidenced by the lack of sharp diffraction peaks. Chen and coworkers have noted that doping $\mathrm{NiB}$ with Fe results in an alloyed material with a greatly diminished broad feature 
around $45^{\circ} 2 \theta$, even with an atomic ratio of $\mathrm{Fe}: \mathrm{Ni}=0.3$, which they attribute to the ability of $\mathrm{Fe}$ to retard the crystallization of $\mathrm{NiB}$ [28]. Likewise, the alloyed material with an atomic ratio of $\mathrm{Fe}: \mathrm{Ni}=1.0$ that we have synthesized here shows no feature for any crystalline phases of $\mathrm{Ni}, \mathrm{Fe}$, or B.

We also used STEM-EDS to ascertain the morphology and elemental location of the FeNiB material. As shown in Fig 2, the alloyed material is comprised of diffuse and irregular particles, while the HRTEM data indicates a mix of nanocrystalline and amorphous regions. Moreover, the EDS map of the catalyst surface demonstrates that $\mathrm{Fe}, \mathrm{Ni}$, and $\mathrm{B}$ are evenly distributed throughout the material, with no areas of elemental agglomeration detected at this scale. Taken together, these data indicate the alloyed nature of the FeNiB material.

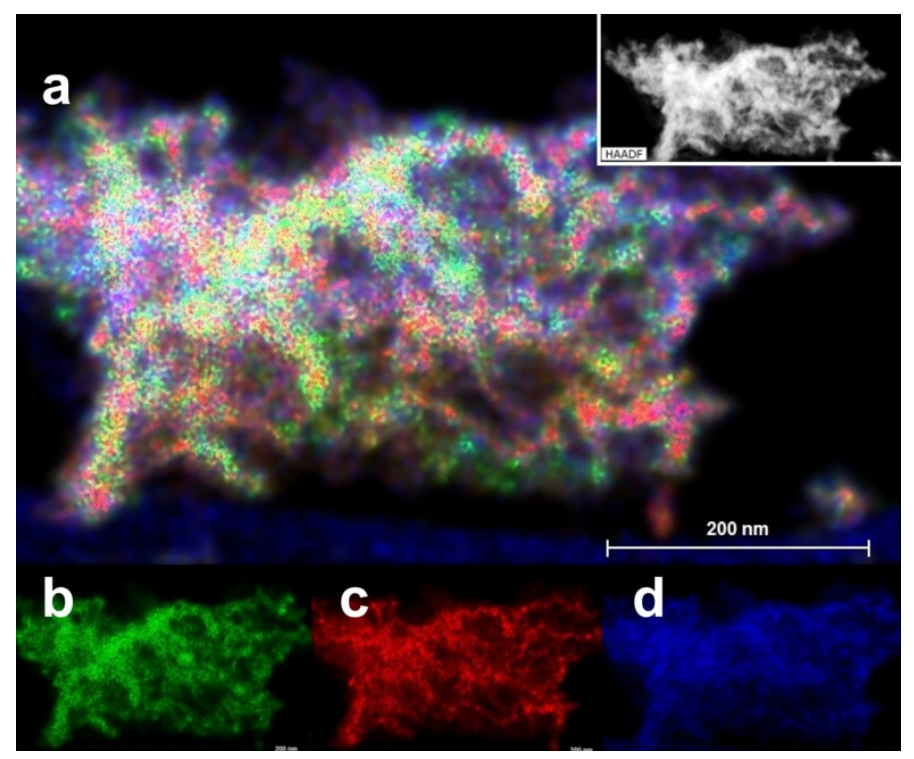

Fig 2. Multimodal STEM-EDS images of (a) as-synthesized FeNiB material and the deconvoluted elemental maps corresponding to (b) Ni, (c) Fe, and (d) B. The high-angle annular dark-field (HAADF) image is included in the inset.

\subsection{CTH of acetophenone}

We investigated the CTH of acetophenone to confirm HDO activity of the putative catalyst species. We chose acetophenone to model the reduction of polar $\mathrm{C}=\mathrm{O}$ bonds in the presence of non-polar $\mathrm{C}=\mathrm{C}$ bonds. Such an experiment would allow us to probe catalyst selectivity for deoxygenation without over-reduction. Each catalyst was suspended in an ethanol solution of acetophenone and naphthalene (internal standard), and the resulting mixture was sealed and 
heated to $320^{\circ} \mathrm{C}$ for $2 \mathrm{~h}$. The results of our initial screening investigations are displayed in Table 1 (related chromatograms can be found in the Supplementary data).

Table 1. Catalytic screening of acetophenone in sc-EtOH using various B-containing catalysts.

\begin{tabular}{|c|c|c|c|}
\hline Catalyst $^{a}$ & $\mathrm{X}(\%)^{b}$ & $\begin{array}{c}\mathbf{Y}(\mathbf{S})(\%)^{c} \\
\mathrm{OH}\end{array}$ & o) ${ }^{c}$ \\
\hline Blank & 10 & $10(100)$ & N.D. ${ }^{d}$ \\
\hline $\mathrm{NiB}$ & 23 & $4(17)$ & $13(57)$ \\
\hline FeB & 42 & $34(81)$ & N.D. \\
\hline Mixture $^{e}$ & 47 & $7(15)$ & $24(51)$ \\
\hline FeNiB & 74 & $7(9)$ & $62(84)$ \\
\hline
\end{tabular}

${ }^{a}$ Reaction conditions: $10 \mathrm{mg}$ catalyst, $100 \mathrm{mg}$ acetophenone, $8 \mathrm{~mL}$ ethanol, $320^{\circ} \mathrm{C}$ for $2 \mathrm{~h}$.

${ }^{b}$ Conversion (X) was measured using GC/MS with naphthalene as an internal standard.

${ }^{c}$ Yield $(\mathrm{Y})$ and selectivity (S) were measured as above.

${ }^{d}$ N.D. $=$ not detected

${ }^{e}$ A physical mixture that contained $5 \mathrm{mg}$ each of as-prepared $\mathrm{NiB}$ and $\mathrm{FeB}$.

As these data demonstrate, the 1:1 alloyed catalyst material displays unique reactivity, given it affords $74 \%$ conversion of acetophenone after $2 \mathrm{~h}$ with $84 \%$ selectivity for ethylbenzene. Apparently, the atomic arrangement of the active site in the alloyed material (and not simply the presence of both metals) is important for selectivity for HDO of acetophenone, given the physical mixture of the monometallic species does not display the same reactivity. We were unable to detect any ring saturation products, which indicates that these metal borides can selectively deoxygenate molecules that contain aromatic moieties. Although we did not quantify it, we could detect 2,3-diphenylbutane when we used the alloyed material. This may indicate that a radical mechanism is operating under these conditions, since 2,3-diphenylbutane would be afforded as the product of the self-condensation of two ethylbenzene radicals (Figure 3). This process would be analogous to Barton-McCombie deoxygenation using Sn-radical species [37].<smiles>CCc1cccc(C(C)C(C)C)c1</smiles>

Fig 3. Hypothetical radical-based process for the deoxygenation of acetophenone.

Deoxygenation of acetophenone to produce an ethylbenzene radical (a) followed by quenching with $\mathrm{H} \bullet$ radical (b) to afford ethylbenzene is analogous to Barton-McCombie deoxygenation. 
Competing self-condensation of the ethylbenzene radical (c) would produce 2,3-diphenylbutane, which was detected using GC/MS.

\subsection{CTH of organosolv lignin}

Given the selective deoxygenation reactivity of the FeNiB alloy, we screened its ability to valorize organosolv lignin derived from hybrid poplar. For these experiments, the catalyst, hexadecane (internal standard), and lignin powder were suspended in ethanol, and the resulting mixture was sealed and heated to $320^{\circ} \mathrm{C}$ for $2 \mathrm{~h}$. After reaction and workup, the afforded lignin product was a brown viscous oil that was readily soluble in ethanol, THF, and methylene chloride. The apparent molecular weights (MWs) obtained by GPC are provided in Fig 4.

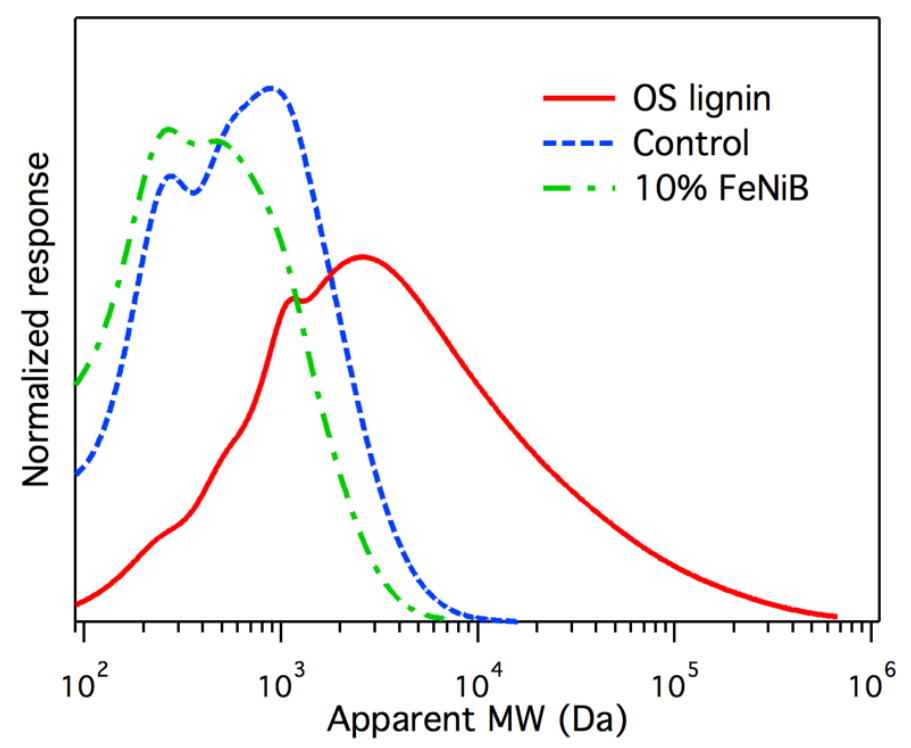

Fig 4. GPC data from catalytic valorization of hybrid poplar organosolv (OS) lignin, including MW distributions for original OS lignin (solid red), the control (without catalyst) lignin (dotted blue), and the catalytically treated (10\% FeNiB) lignin (dashed green). Treatment conditions were $320^{\circ} \mathrm{C}$ for $2 \mathrm{~h}$.

We conducted a control reaction in which the lignin sample was heated to temperature in the absence of catalyst to examine un-catalyzed deconstruction of lignin in sc-EtOH. As shown in Fig 4, the organosolv lignin has a number-average molecular weight $\left(\mathrm{M}_{\mathrm{n}}\right)$ of $1800 \mathrm{Da}$ and a polydispersity (PDI) of 3.8, indicative of its broad MW distribution. Upon heating in sc-EtOH, the organosolv lignin experiences a shift to lower $\mathrm{MW}\left(\mathrm{M}_{\mathrm{n}}=406\right.$, PDI $\left.=2.3\right)$, which is likely 
due to partial thermal decomposition of the lignin [38]. The apparent MW of the lignin subjected to catalytic deconstruction using the FeNiB alloy undergoes further deconstruction to afford material with a lower MW $\left(\mathrm{M}_{\mathrm{n}}=317 \mathrm{Da}, \mathrm{PDI}=2.1\right)$.

We examined the lignin deconstruction products using GC/MS to ascertain the ability of the catalysts to deoxygenate the monomeric compounds (Fig 5). Small MW compounds from lignin retain their aromatic character as well as aromatic hydroxyl groups, as is the case for phenol (1), guaiacol (2), and syringol (6). In addition, there are several lignin monomer species present that retain an alkyl sidechain (e.g. complexes 3-5, 7, 8, 12, and 19), and in these cases, these side chains have been completely deoxygenated in a manner analogous to the acetophenone model compound above. There are also esterified products present (e.g. complexes 14 and 17) that likely result from reactions between the corresponding lignin species and either ethanol (reaction solvent) or acetaldehyde formed from dehydrogenation of ethanol.
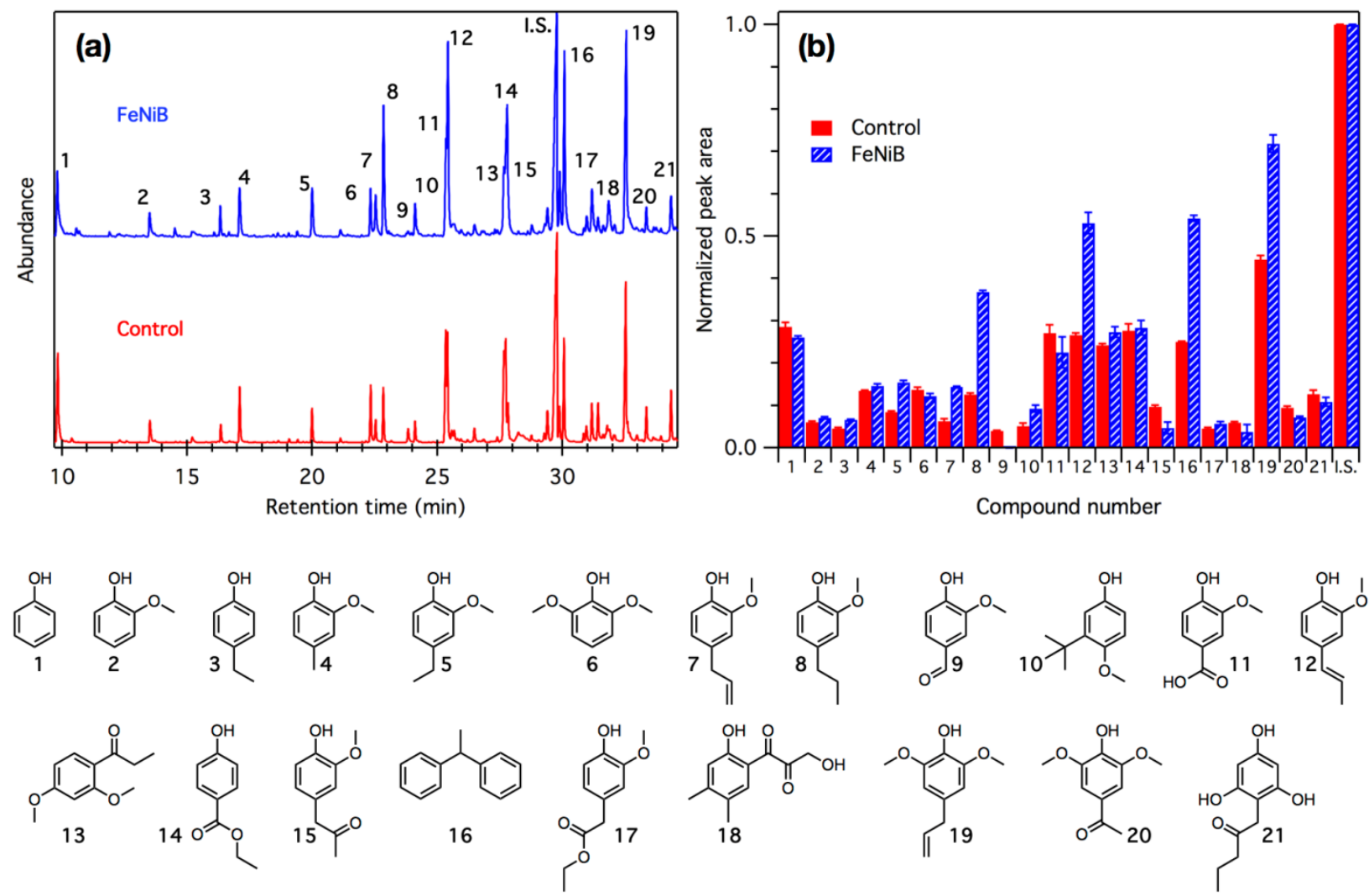

Fig 5. (a) Gas chromatograms of the product slate afforded from $\mathrm{CTH}$ of organosolv lignin treated in the presence of the FeNiB catalyst (blue) and in the absence of any catalyst (control, red) at $320^{\circ} \mathrm{C}$ with hexadecane as an internal standard. Identified peaks are numbered and shown at the bottom. (b) Comparison of the normalized peak areas of each of the numbered products. 
Area values are derived from the average of 3 replicates and error bars denote the standard deviation of these calculations.

We used hexadecane as an internal standard to allow comparisons of peak areas between the reaction with and without catalyst. The peak areas were calculated as an average value from three replicates and were normalized to the peak area of the internal standard. This methodology allowed us to determine statistically significant changes in peak area between the two reactions (with and without catalyst). As shown in Fig 5b, this semi-quantitative analysis demonstrates some trends in reactivity. For instance, in the presence of the FeNiB catalyst, there is a substantial increase in the amounts of compounds that contain deoxygenated aliphatic sidechains such as 8, 12, and 19. Moreover, there is a decrease in the amounts of compounds that contain oxygenated sidechains such as $\mathbf{9 , 1 1 , 1 5}$, and 20. These trends agree with our model compound study, given the ability of the FeNiB catalyst to deoxygenate acetophenone to ethylbenzene.

GC/MS is a powerful technique to characterize and quantify small MW components with chemical features that are compatible with the column and experimental parameters used. However, solubility, MW, and polarity issues preclude the use of this technique for direct analysis of oligomeric organosolv lignin. For this purpose, we found ${ }^{1} \mathrm{H}-{ }^{13} \mathrm{C}$ HSQC NMR spectroscopy particularly well suited, as it allows for a direct qualitative comparison of pre- and post-reaction lignin. The side-chain and interunit regions of the NMR spectra of organosolv, control, and catalytically valorized lignin samples are shown in Figure 6. 


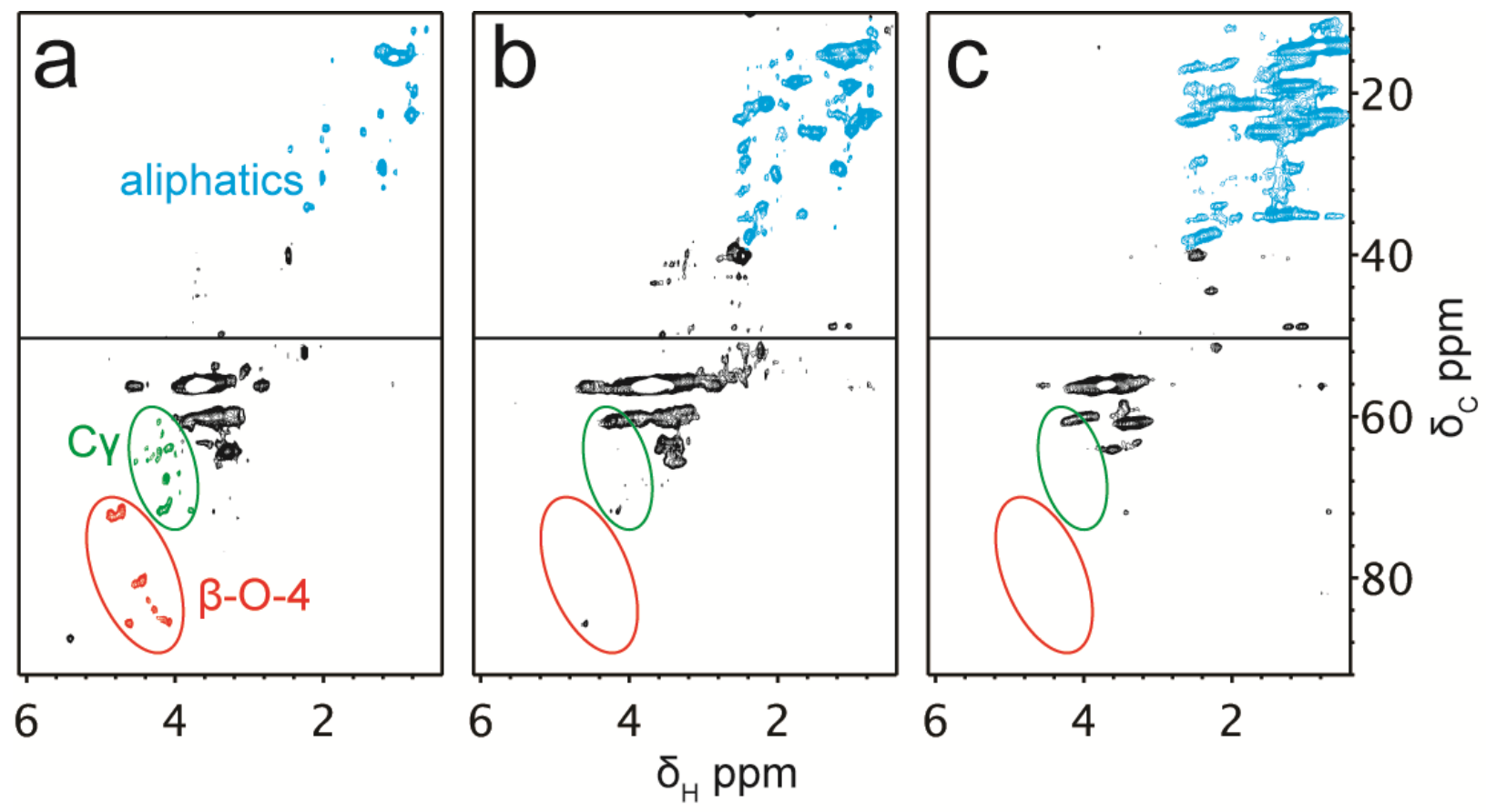

Fig 6. HSQC NMR spectra of organosolv (a), control (no catalyst) (b), and catalytically valorized (c) lignin samples depicting the aliphatic side-chain (top panels) and interunit linkage (bottom panels) regions. Signals pertaining to $\beta$-O-4 linkages, $\gamma$-ether and $\gamma$-ester groups, and deoxygenated aliphatic hydrocarbons are colored red, green, and blue, respectively.

As expected, qualitative trends pertaining to the depolymerization of organosolv lignin are evident in the interunit region of the NMR spectra. Chemical shifts for $\mathrm{H}-\mathrm{C}_{\alpha}$ and $\mathrm{H}-\mathrm{C}_{\beta}$ in $\beta-\mathrm{O}-4$ linkages (Fig 6, red peaks) are completely absent in the spectra associated with the control and catalytically valorized lignin samples. Hydrogenolysis of these linkages contributes to the reduction in apparent MW of the treated fractions (Fig 4) as well as the disappearance of the associated peaks in the NMR spectra. Moreover, deoxygenation of the aliphatic side chains in the oligomeric species manifest as a disappearance of resonances associated with $\mathrm{H}-\mathrm{C}_{\gamma}$ species. Peaks associated with oxygenated $\mathrm{H}-\mathrm{C}_{\gamma}$ species, including $\gamma$-ether and $\gamma$-ester groups [36], are absent in the spectra of the treated samples (Fig 6, green peaks). In addition, an increase in the number and linewidth of signals in the aliphatic region of the NMR spectra (Fig 6, blue peaks) is indicative of the increased presence of deoxygenated alkyl side chains, such as $-\mathrm{C}_{\alpha} \mathrm{H}_{2}-\mathrm{C}_{\beta} \mathrm{H}_{3}$ as in 5, $-\mathrm{C}_{\alpha} \mathrm{H}_{2}-\mathrm{C}_{\beta} \mathrm{H}_{2}-\mathrm{C}_{\gamma} \mathrm{H}_{3}$ as in 7, $-\mathrm{C}_{\alpha} \mathrm{H}=\mathrm{C}_{\beta} \mathrm{H}-\mathrm{C}_{\gamma} \mathrm{H}_{3}$ as in 9, or $-\mathrm{C}_{\alpha} \mathrm{H}_{2}-\mathrm{C}_{\beta} \mathrm{H}=\mathrm{C}_{\gamma} \mathrm{H}_{2}$ as in 13.

\section{Conclusion}


Amorphous B-containing FeNi alloys can mediate selective catalytic transfer hydrogenolysis of ketones to alkanes in the presence of aromatic rings using supercritical ethanol as the solvent and hydrogen donor. This contrasts with the monometallic Ni- or Fe-containing species, which afford the transfer hydrogenation (alcohol) product with lower conversion of the starting material. We have also employed the bimetallic B-containing material for the catalytic valorization of organosolv lignin. Treatment of hybrid poplar lignin affords a product slate enriched with monomeric alkyl phenols without the addition of exogenous hydrogen. We have demonstrated the utility of CTH of lignin using a biomass-derived non-toxic solvent system, which is a lignin valorization strategy that will undoubtedly garner further attention. Moreover, these catalyst species are potential candidates for RCF processes, which are used to generate lignin monomeric species directly and selectively from whole biomass. These experiments, as well as attempts to elucidate catalyst durability, recyclability, and mechanism are ongoing in our laboratory.

\section{Acknowledgments}

This project was supported by the Southeastern Sun Grant Center and the US Department of Transportation, Research and Innovative Technology Administration DTO559-07-G-00050. N.L. and S.C.C. also acknowledge the Southeastern Partnership for Integrated Biomass Supply Systems (IBSS), which is supported by AFRI 2011-68005-30410 from USDA NIFA. STEM-

EDS was performed at the Vanderbilt Institute for Nanoscience and Engineering (VINSE) using an instrument procured using funds provided by the NSF (NSF EPS 1004083 TN-SCORE). The authors would also like to thank Ms. Choo Hamilton, Ms. Alex Peeden, and Dr. Maulik Patel (UT) for assistance with ICP, GPC, and XRD.

\section{References}

[1] A.J. Ragauskas, G.T. Beckham, M.J. Biddy, R. Chandra, F. Chen, M.F. Davis, B.H. Davison, R.A. Dixon, P. Gilna, M. Keller, P. Langan, A.K. Naskar, J.N. Saddler, T.J. Tschaplinski, G.A. Tuskan, C.E. Wyman, Science 344 (2014) 1246843. [2] J. Zakzeski, P.C.A. Bruijnincx, A.L. Jongerius, B.M. Weckhuysen, Chem. Rev. 110 (2010) 3552-3599.

[3] R. Rinaldi, R. Jastrzebski, M.T. Clough, J. Ralph, M. Kennema, P.C.A. Bruijnincx, B.M. Weckhuysen, Angew. Chem. Int. Ed. 55 (2016) 8164-8215.

[4] L. Shuai, M.T. Amiri, Y.M. Questell-Santiago, F. Heroguel, Y.D. Li, H. Kim, R. Meilan, C. Chapple, J. Ralph, J.S. Luterbacher, Science 354 (2016) 329-333. 
[5] V. Molinari, G. Clavel, M. Graglia, M. Antonietti, D. Esposito, ACS Catal. 6 (2016) 16631670.

[6] E.M. Anderson, R. Katahira, M. Reed, M.G. Resch, E.M. Karp, G.T. Beckham, Y. RománLeshkov, ACS Sust. Chem. Eng. (2016).

[7] P. Ferrini, R. Rinaldi, Angew. Chem. Int. Ed. 53 (2014) 8634-8639.

[8] M.V. Galkin, S. Sawadjoon, V. Rohde, M. Dawange, J.S.M. Samec, Chemcatchem 6 (2014) 179-184.

[9] T.H. Parsell, B.C. Owen, I. Klein, T.M. Jarrell, C.L. Marcum, L.J. Haupert, L.M. Amundson, H.I. Kenttamaa, F. Ribeiro, J.T. Miller, M.M. Abu-Omar, Chem. Sci. 4 (2013) 806-813.

[10] T. Renders, S. Van den Bosch, T. Vangeel, T. Ennaert, S.-F. Koelewijn, G. Van den Bossche, C.M. Courtin, W. Schutyser, B.F. Sels, ACS Sust. Chem. Eng. (2016).

[11] Q. Song, F. Wang, J.Y. Cai, Y.H. Wang, J.J. Zhang, W.Q. Yu, J. Xu, Energ. Environ. Sci. 6 (2013) 994-1007.

[12] S. Van den Bosch, W. Schutyser, R. Vanholme, T. Driessen, S.F. Koelewijn, T. Renders, B. De Meester, W.J.J. Huijgen, W. Dehaen, C.M. Courtin, B. Lagrain, W. Boerjan, B.F. Sels, Energ. Environ. Sci. 8 (2015) 1748-1763.

[13] J.J. Bozell, Science 329 (2010) 522-523.

[14] J.J. Bozell, S.K. Black, M. Myers, D. Cahill, W.P. Miller, S. Park, Biomass Bioenerg. 35 (2011) 4197-4208.

[15] J.M. Tao, O. Hosseinaei, L. Delbeck, P. Kim, D.P. Harper, J.J. Bozell, T.G. Rials, N. Labbe, Rsc Adv 6 (2016) 79228-79235.

[16] S. De, B. Saha, R. Luque, Bioresource Technol. 178 (2015) 108-118.

[17] M.J. Gilkey, B.J. Xu, ACS Catal. 6 (2016) 1420-1436.

[18] E. Brunner, J Chem. Eng. Data 30 (1985) 269-273.

[19] D. Wang, D. Astruc, Chem. Rev. 115 (2015) 6621-6686.

[20] S. Brand, J. Kim, Energy 80 (2015) 64-74.

[21] S. Brand, R.F. Susanti, S.K. Kim, H.S. Lee, J. Kim, B.I. Sang, Energy 59 (2013) 173-182. [22] K. Barta, T.D. Matson, M.L. Fettig, S.L. Scott, A.V. Iretskii, P.C. Ford, Green Chem. 12 (2010) 1640-1647.

[23] T.S. Hansen, K. Barta, P.T. Anastas, P.C. Ford, A. Riisager, Green Chem. 14 (2012) 24572461.

[24] X.Y. Wang, R. Rinaldi, Energ. Environ. Sci. 5 (2012) 8244-8260.

[25] M. Kim, J.M. Ha, K.Y. Lee, J. Jae, Catal. Commun. 86 (2016) 113-118.

[26] S. Carenco, D. Portehault, C. Boissiere, N. Mezailles, C. Sanchez, Chem. Rev. 113 (2013) 7981-8065.

[27] Y. Pei, G.B. Zhou, N. Luan, B.N. Zong, M.H. Qiao, F. Tao, Chem. Soc. Rev. 41 (2012) 8140-8162.

[28] Y.W. Chen, N. Sasirekha, Ind. Eng. Chem. Res. 48 (2009) 6248-6255.

[29] W.Y. Wang, Y.Q. Yang, H.A. Luo, T. Hu, W.Y. Liu, Catal. Commun. 12 (2011) 436-440.

[30] W.Y. Wang, Y.Q. Yang, J.G. Bao, H.A. Luo, Catal. Commun. 11 (2009) 100-105.

[31] W.Y. Wang, Y.Q. Yang, H.A. Luo, W.Y. Liu, Catal. Commun. 11 (2010) 803-807.

[32] W.Y. Wang, Y.Q. Yang, H. Luo, H.Z. Peng, F. Wang, Ind. Eng. Chem. Res. 50 (2011) 10936-10942.

[33] B. Loubinoux, M. Heitz, G. Coudert, G. Guillaumet, Tetrahedron Lett. 21 (1980) 49914994.

[34] M. Nie, Y.C. Zou, Y.M. Huang, J.Q. Wang, Int. J. Hydrogen Energ. 37 (2012) 1568-1576. 
[35] A. Guerra, L.A. Lucia, D.S. Argyropoulos, Holzforschung 62 (2008) 24-30.

[36] J.J. Bozell, C.J. O'Lenick, S. Warwick, J. Agr. Food Chem. 59 (2011) 9232-9242.

[37] D.H.R. Barton, S.W. Mccombie, J. Chem. Soc. Perk. T. 1 (1975) 1574-1585.

[38] M.R. Sturgeon, M.H. O'Brien, P.N. Ciesielski, R. Katahira, J.S. Kruger, S.C. Chmely, J.

Hamlin, K. Lawrence, G.B. Hunsinger, T.D. Foust, R.M. Baldwin, M.J. Biddy, G.T. Beckham, Green Chem. 16 (2014) 824-835.

TOC Graphic:

\section{Catalytic transfer hydrogenolysis of acetophenone}

\begin{tabular}{|c|c|}
\hline $\begin{array}{l}\text { Control } \\
\text { FeB }\end{array}$ & $\begin{array}{l}\text { \% Yield: } \\
\text { ethylbenzene } \\
\text { 1-phenylethanol }\end{array}$ \\
\hline NiB & \\
\hline Mixture & \\
\hline FeNiB all & \\
\hline
\end{tabular}

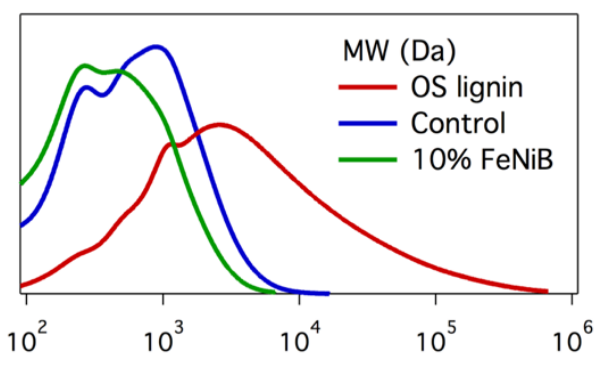

Deconstruction and valorization of hybrid poplar lignin 